\title{
Analysis of Ship Noise Characteristics Generated According to Sailing Conditions of the G/T 1000-ton Stern Fishing Trawler
}

\author{
Tae-ho Lee ${ }^{1}\left(\mathbb{D}\right.$, Nam-u Lee $^{2}$, Dae-jae Lee ${ }^{3}$ and Bong-kyu Jung ${ }^{4, *}$ \\ 1 Department of Power Plant, Korea Polytechnic College, Muan 58542, Korea; leeth@kopo.ac.kr \\ 2 Department of Ship Operating Center, Gyeongsang National University, Tongyeong 53064, Korea; \\ nuspssbd@hanmail.net \\ 3 Department of Marine Production System Management, Pukyong National University, Busan 48513, Korea; \\ daejael@pknu.ac.kr \\ 4 Department of Marine Police System, Gyeongsang National University, Tongyeong 53064, Korea \\ * Correspondence: bkjung@gnu.ac.kr; Tel.: +82-55-772-9185
}

Citation: Lee, T.-h.; Lee, N.-u.; Lee, D.-j.; Jung, B.-k. Analysis of Ship Noise Characteristics Generated According to Sailing Conditions of the G/T 1000-ton Stern Fishing Trawler. J. Mar. Sci. Eng. 2021, 9, 914. https://doi.org/10.3390/jmse9080914

Academic Editor: Francesco

Tiralongo

Received: 14 July 2021

Accepted: 21 August 2021

Published: 23 August 2021

Publisher's Note: MDPI stays neutral with regard to jurisdictional claims in published maps and institutional affiliations.

Copyright: (C) 2021 by the authors Licensee MDPI, Basel, Switzerland. This article is an open access article distributed under the terms and conditions of the Creative Commons Attribution (CC BY) license (https:// creativecommons.org/licenses/by/ $4.0 /)$

\begin{abstract}
In this study, we conducted onboard noise measurement experiments under the conditions of anchoring, sailing, casting, and hauling to determine whether noise generated in the G/T 1000-ton fishing trawler triggers zone-specific effects upon vessel operation. It was shown that most accommodation areas of the trawler comfortably met the IMO acceptance criteria regardless of the sailing condition, but most of the stern area, where the fishing actually occurs, exceeded the permitted limit of $75 \mathrm{~dB}$ (A). Furthermore, the statistical analysis revealed a significant difference $(p<0.05)$ only in the bow and the stern, which are both open areas. In the case of the former, improvements were deemed possible due to the influence of the fluid emission noise from the seawater piping in the bow, and the acceptance criteria were also appropriate. However, in the case of the latter, a significant difference was seen in hauling conditions, and on-site analysis confirmed frictional noise from hydraulic oil in the trawl winch and between the chains and the metal hull, leading to the conclusion that various improvements are required, such as the mandatory wearing of safety equipment by workers and stricter legal standards for permitted noise levels.
\end{abstract}

Keywords: trawl vessel; ship noise; winch drum; analysis of variance; engine control room (ECR); fishing vessel; otter board; poop deck; international maritime organization (IMO)

\section{Introduction}

Since vessels operate in isolation in the sea unlike typical mainland mechanical facilities or plant systems, sailors who are on board for long periods experience stress and anxiety arising from exposure to intense levels of work under poor conditions (i.e., deck, bridge, engine room), such as in the cramped cabins, isolation, and physical fatigue, which negatively influence a healthy sailing life [1].

Most ocean-going vessels continuously sail for the transportation of cargo and passengers or undergo jobs involving acquisition of marine resources from the sea. Therefore, sailors on said ships are constantly exposed to noise and vibrations generated from the operation of the main engine and various assistive mechanical devices [2].

In the case of fishing vessels, marine resources in open waters must be continuously acquired, meaning that the workers must undergo repetitive fishing work and are exposed to intensive work environments. This implies that the sailors' health is directly related to the performance of the boat. In fact, many Korean sailors working on fishing vessels are voicing their concerns regarding the lack of onboard space and the irregular and insufferable work environments [3].

Therefore, to regulate noise generated in vessels, the International Maritime Organization (IMO) has adopted and applied a code that has a limit for tolerable noise generated in areas such as cabins, accommodation areas, and the engine room [4]. 
Furthermore, the noise generated by the vessel has been shown to affect marine life as it is also emitted underwater [5], and the IMO has recommended procedures for reducing the level of radiation emitted underwater [6].

As stated previously, noise generated in vessels exerts a negative influence on the sailors' health and/or marine life, depending on the source, suggesting a high need for reduction of noise levels.

If the human body is exposed to noise for a long period of time, various complex side effects, such as hearing loss, deafness, tinnitus, cardiovascular effects, sleep disturbances, and learning difficulties, can arise [7]. In accommodation areas, residents will feel uncomfortable if the noise level exceeds $55 \mathrm{~dB}(\mathrm{~A})$. Their ability to listen will be disrupted if the noise level exceeds $65 \mathrm{~dB}(\mathrm{~A})$, and if it exceeds $90 \mathrm{~dB}(\mathrm{~A})$, they might suffer from deafness [8].

As mentioned, noise has a huge effect on the human body, but over $40 \%$ of sailors working on ships do not regard the environmental issues of noise as important, which means there is a need to improve the perception of sailors to motivate them to protect their health from noise in the ship [9].

Moreover, whereas marine transportation via ship is gradually increasing, studies on port noise from ships and relevant regulations are insufficient, compared to railroads, roads, and airfields. For this reason, some EU countries investigated noise outside of ships and suggested environmental improvement plans through the INTERREG maritime program [10,11].

Environmental pollution caused by oil, exhaust gas, fouling paints, etc. from ships has been strictly controlled for years, but awareness of environmental issues regarding noise only recently came to the fore. Accordingly, the EU supported the FP7-SILENV project from 2010 to 2012 [12], and systematic studies on the effect of environmental noise on ports were conducted focusing on certain advanced European countries [13-15]. They also analyzed the effect of noise from ships moving in a port on the port itself and on residents living in surrounding accommodation sites [16,17].

Recently, various studies to improve the noise problem in vessels have been conducted. Park et al. suggested the application of a separate side-branch resonator to resolve the blade passing frequency (BPF) noise generated in air conditioning facilities and axial fan devices, which are essential in vessels, to suppress vessel noise [18].

Kim et al. acknowledged the need to introduce regulations regarding noise control in naval ships smaller than $24 \mathrm{~m}$ that are not passenger or merchant ships, and they suggested that noise can be measured using the ISO-14509-1 pass-by measurement procedures [19].

Some researchers attempted to conduct noise analysis based on the load operation of the generator in a 1500-ton electrically-powered oceanographic research vessel, and they suggested the need for various regulatory standards of noise that occur in different types of vessels since the mechanism of vessel propulsion is continuously evolving [20].

The aforementioned research was mainly relevant to merchant ships, warships, and special ships rather than fishing vessels.

Moreover, according to a comparative study on the noise of merchant ships, such as general cargo and roro-ship, berthed in ports, the noise varied highly depending on the type and weight of the ship [21].

Although a similar study was conducted on the noise effect on sailors of a 1700-ton fishing trawler in the accommodation area, only noise during the sailing of the fishing trawler was measured, which did not provide any details on the noise generated during fishing [22].

As basic research to establish the noise acceptance criteria for fishing vessels, a study on indoor noise generated in a 300-ton squid-fishing vessel was conducted to compare and determine whether the suitability of the IMO acceptance criteria for ordinary merchant ships holds up indoors. As a result, it was suggested that the setting for the fishing vessel is approximately $5 \mathrm{~dB}(\mathrm{~A})$ higher than that of the general ship [2]. 
Another interesting study was conducted by Park, where they researched the shipboard noise caused by the sailors hitting the hull with metal bats or the engine idling during a fishing operation involving attracting anchovies to the surface with a fishing lamp in a 6-ton FRP vessel near Jeju Island of South Korea [23]. However, this was a very special case of subminiature fishing vessels belonging to local fishermen of a traditional fishing background, meaning that this case is somewhat irrelevant to our research.

The general research trend regarding noise in fishing vessels, as the above, suggests a lack of detailed research on noise in relation to the work of the vessel. Studies involving small and high-speed fishing vessels exist, but those related to 1000-ton fishing vessels do not.

This is due to the fact that unlike merchant ships that require stable sailing at a constant speed, fishing vessels achieve profitability by repeatedly acquiring catches at sea, suggesting tight operation times and high safety risks, making it realistically difficult to conduct smooth noise measurement experiments.

Therefore, in this study, we compared and analyzed characteristics of actual noise generated in a 1000-ton stern trawl fishing vessel with sailing straight at $85 \%$ engine load, when undergoing trawling (casting and hauling) and when at anchor. Moreover, this study aims to clarify the purpose of protecting the health of sailors from ship noise and explain diverse cases of noise depending on the operating conditions of fishing vessels.

\section{Materials and Methods}

\subsection{The selected Fishing Trawler}

The target vessel of this study is a 999-ton stern trawler with a total length of $70.57 \mathrm{~m}$, a typical crew of 20-30 but with a maximum capacity of 108 passengers, and a main engine output of $3300 \mathrm{hp}$. The maximum speed of the main engine is $650 \mathrm{rpm}$, and hull and engine mounts are equipped with vibration dampers that can reduce vibrations. The trawl winch is operated by fixing a hydraulic clutch to the main engine [24], and the data and specifications of the experimental vessel are shown in Table $1[24,25]$.

Table 1. Principal particulars of trawl fishing vessel.

\begin{tabular}{ccc}
\hline List & Type & Specification \\
\hline Length & $L_{O A}$ & $70.57 \mathrm{~m}$ \\
& $L_{B P}$ & $60.60 \mathrm{~m}$ \\
Breadth & MLD & $12.30 \mathrm{~m}$ \\
Depth & Upper deck & $7.40 \mathrm{~m}$ \\
& 2nd deck & $5.00 \mathrm{~m}$ \\
Gross tonnage & National & $999 \mathrm{t}$ \\
& International & $1358 \mathrm{t}$ \\
Ship speed & 85\% MCR (for Sea trial) & $14.11 \mathrm{knot}$ \\
Crew & Max. on board & $108 \mathrm{p}$ \\
Main engine & 6MG34HX & $3300 \mathrm{ps}$ \\
Aux engine & S165L-EN & $600 \mathrm{ps}$ \\
Propeller & KT-32B C.P.P & $4-\mathrm{blade}$ \\
\hline
\end{tabular}

Trawl fishing vessels acquire catches by casting nets attached with heavy otter boards below sea level through a winch mounted on the stern deck, followed by hauling the net by winding it up at a speed of 3-4 knots. The number of daily operations varies depending on the size of the fishery and the vessel, but the average is $3 \sim 4$ times, with one operation taking approximately $4 \mathrm{~h}$ to complete, although the duration is dependent on geographical, environmental, and other vessel characteristics [26].

During trawl fishing, resistance occurs in the net and the otter board connected to a warp of a length of a few hundred meters, which is dropped in the direction of the stern underwater or to the seafloor depending on the water depth [27]. This is believed to also influence the machine loading and vessel noises. Figure 1 illustrates the schematic diagram of a fishing operation of a trawl fishing vessel [26]. 


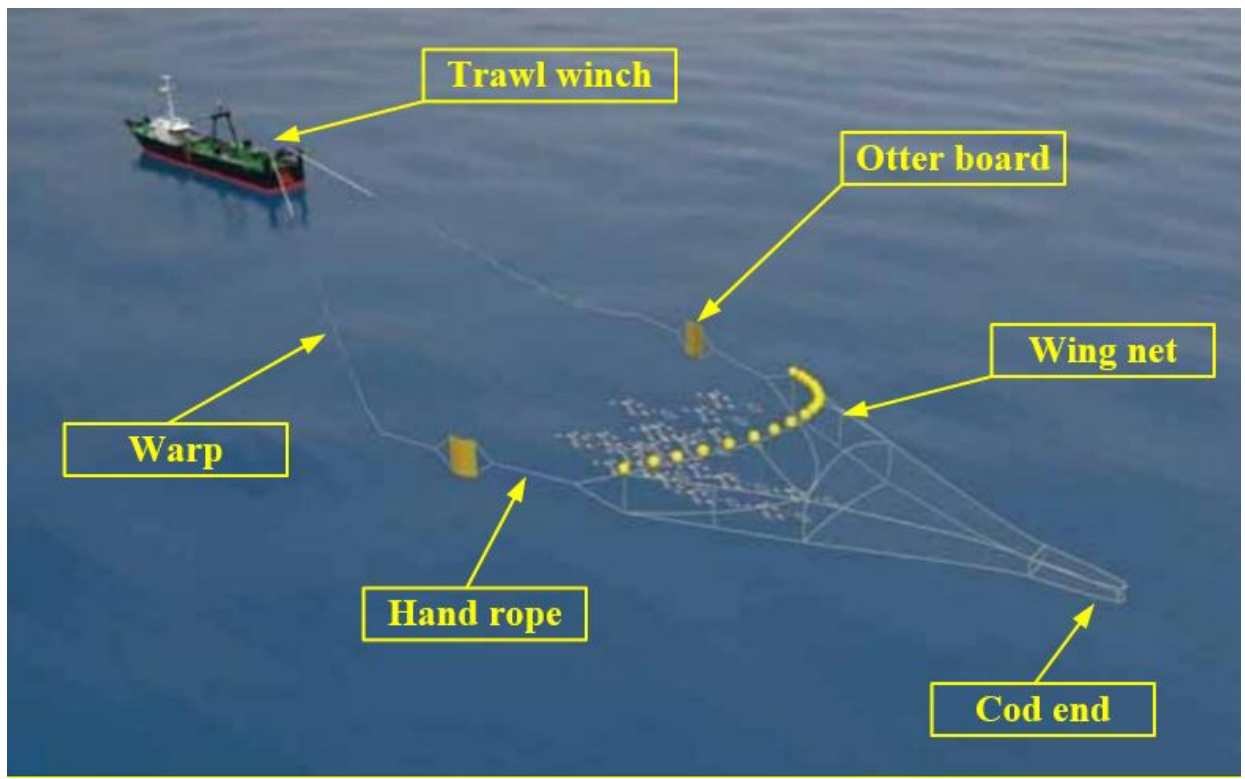

Figure 1. Schematic diagram of fishing operation of stern fish trawler.

To conduct this study, we designated 10 areas within the vessel and allocated symbols $\mathrm{N} 1$ to N10 to each of the areas, set as areas where the crew spends a lot of their time, as shown in Figure 2. In the case of the cabins, the one located below sea level from the center of the vessel was referred to as Cabin (A), and the one above sea level as Cabin (B). The selected open areas were those of the bow and the stern. However, open areas of IMO are presented as open recreation areas. In the case of a stern, the trawler is a working area, therefore, IMO guidelines need to be updated. In the case of the engine areas, the central section and trawl winch clutch area of the engine room were selected. Since the regulatory standards for vessel noise vary by area, the IMO noise regulation criteria and locations that correspond to the tonnage of the vessel are briefly listed in Table 2 [28].

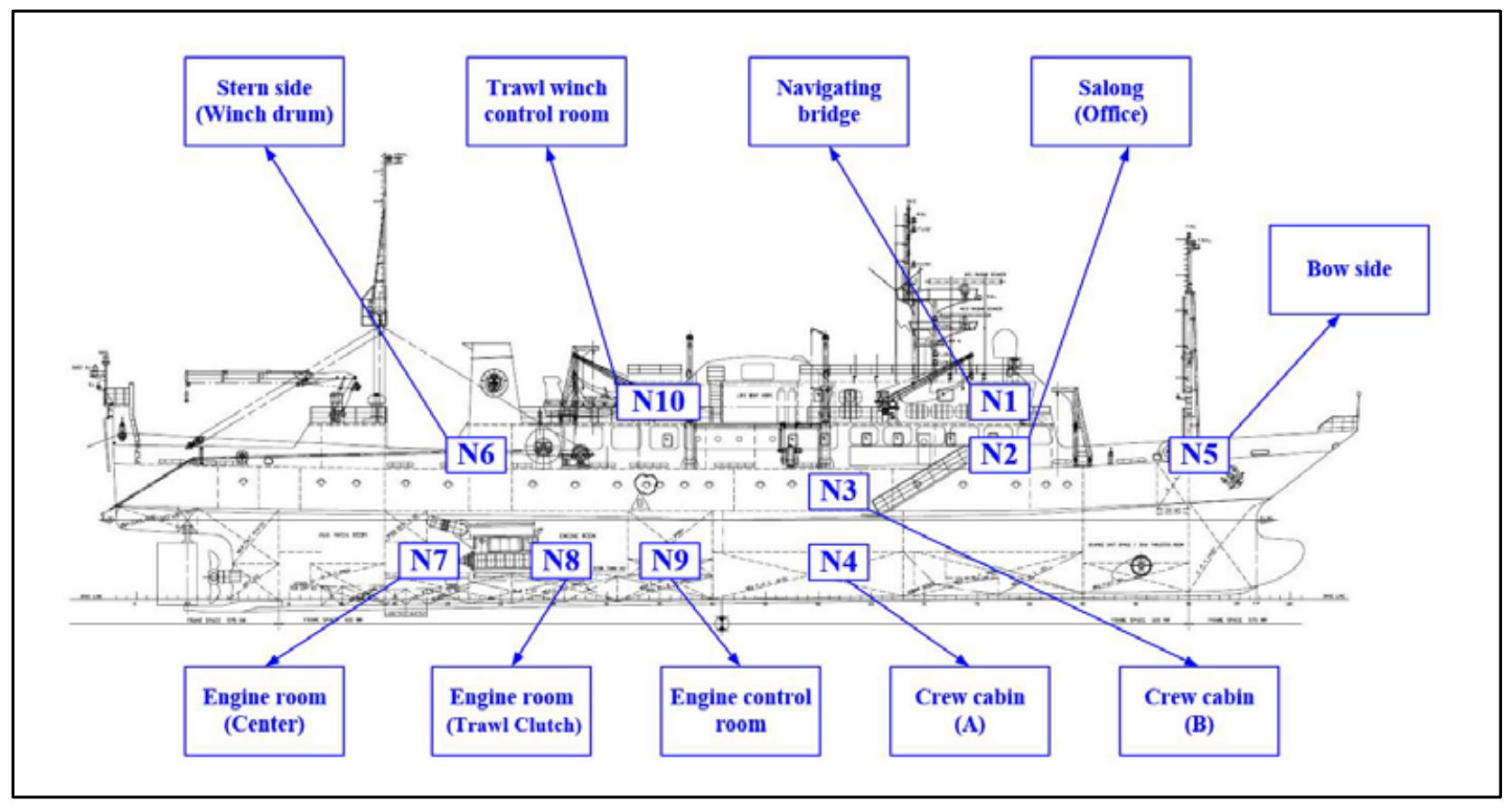

Figure 2. Location and area code of areas where noise measurements are taken. 
Table 2. Areas for measurements in the trawl fishing vessel according to IMO noise acceptance criteria for each location.

\begin{tabular}{cccc}
\hline Location & Limits (dB (A)) & Number & $\begin{array}{c}\text { Measurement Trawl } \\
\text { Vessel Zone }\end{array}$ \\
\hline Navigating bridges & 60 & $\mathrm{~N} 1$ & Bridge \\
Offices & 65 & $\mathrm{~N} 2$ & Salong \\
Cabins & 60 & $\mathrm{~N} 3, \mathrm{~N} 4$ & Cabin (A), (B) \\
Open deck recreation areas & 75 & $\mathrm{~N} 5, \mathrm{~N} 6$ & Bow side, Stern side \\
Machinery spaces & 110 & $\mathrm{~N} 7, \mathrm{~N} 8$ & E/R center, E/R trawl clutch \\
Machinery control rooms & 75 & $\mathrm{~N} 9$ & Engine control room (ECR) \\
Control stations & 65 & $\mathrm{~N} 10$ & Trawl winch control room (TCR) \\
\hline
\end{tabular}

\subsection{Experimental Equipment and Procedures}

The sound level meter to be used in the vessel must satisfy the IEC 61672-1 condition of IMO, and the microphone must be equipped with a windscreen to minimize wind intervention [29]. Table 3 portrays the brief specifications of the sound level meter. Its measurement range is $24-139 \mathrm{~dB}(\mathrm{~A})$, and weighted measurements can be taken in unit time. The $1: 3$ octave band $(6.3-20,000 \mathrm{~Hz})$ function can be used, and calibration is possible before usage [30].

Table 3. Specifications of the sound level meter.

\begin{tabular}{ccc}
\hline List & Specification & Unit \\
\hline Type & CR:171B & Class 2 \\
Applicable standard & IEC-61672-1:2013 & - \\
A-Weighted Range & $24-139$ & $\mathrm{~dB}(\mathrm{~A})$ \\
Resolution & 0.1 & $\mathrm{~dB}(\mathrm{~A})$ \\
1:3 Octave band & $6.3-20,000$ & $\mathrm{~Hz}$ \\
Weight & 300 & $\mathrm{~g}$ \\
\hline
\end{tabular}

It can also be presented as octave bands between $31.5-8 \mathrm{kHz}$ if necessary, and the measurement time must be over $15 \mathrm{~s}$ so that a stable value can be obtained. The measurement height must be within $1.2-1.6 \mathrm{~m}$, and the device must be always at least $0.5 \mathrm{~m}$ from the boundary. These main standards for noise measurement using IMO MSC. 337(91) are equally applied by the Korean Register of Shipping, the domestic authorized ship inspection company [29].

Figure 3 illustrates the sailing route used in the actual experiment. The vessel took the sea route near the sea coordinates of N $33.30^{\prime} 000^{\prime \prime}-\mathrm{E} 127.30^{\prime} 000^{\prime \prime}$ in the vicinity of the southwestern sea of Korea. The sea conditions satisfied noise measurement standards during the actual experiment, and the experimental conditions including detailed operational conditions of the vessel are listed in Table 4.

Table 4. Experimental condition of the trawler.

\begin{tabular}{|c|c|c|c|c|c|c|}
\hline List & Item & Anchoring & Sailing & Casting & Hauling & Unit \\
\hline \multirow{4}{*}{ Weather } & Wind scale & \multicolumn{4}{|c|}{$3-4$} & beaufort \\
\hline & Wave height & \multicolumn{4}{|c|}{$0.5-1.5$} & $\mathrm{~m}$ \\
\hline & Water depth & \multicolumn{4}{|c|}{$40-90$} & $\mathrm{~m}$ \\
\hline & Weather & \multicolumn{4}{|c|}{ Cloudy } & - \\
\hline \multirow{3}{*}{$\begin{array}{c}\text { Ship } \\
\text { condition }\end{array}$} & Speed & 0.0 & 14.25 & 3.35 & 3.65 & knot \\
\hline & Engine load & 0.0 & 86.50 & 24.50 & 25.70 & $\%$ \\
\hline & Experiment date & & \multicolumn{4}{|c|}{10 May 2021-18 May 2021} \\
\hline
\end{tabular}




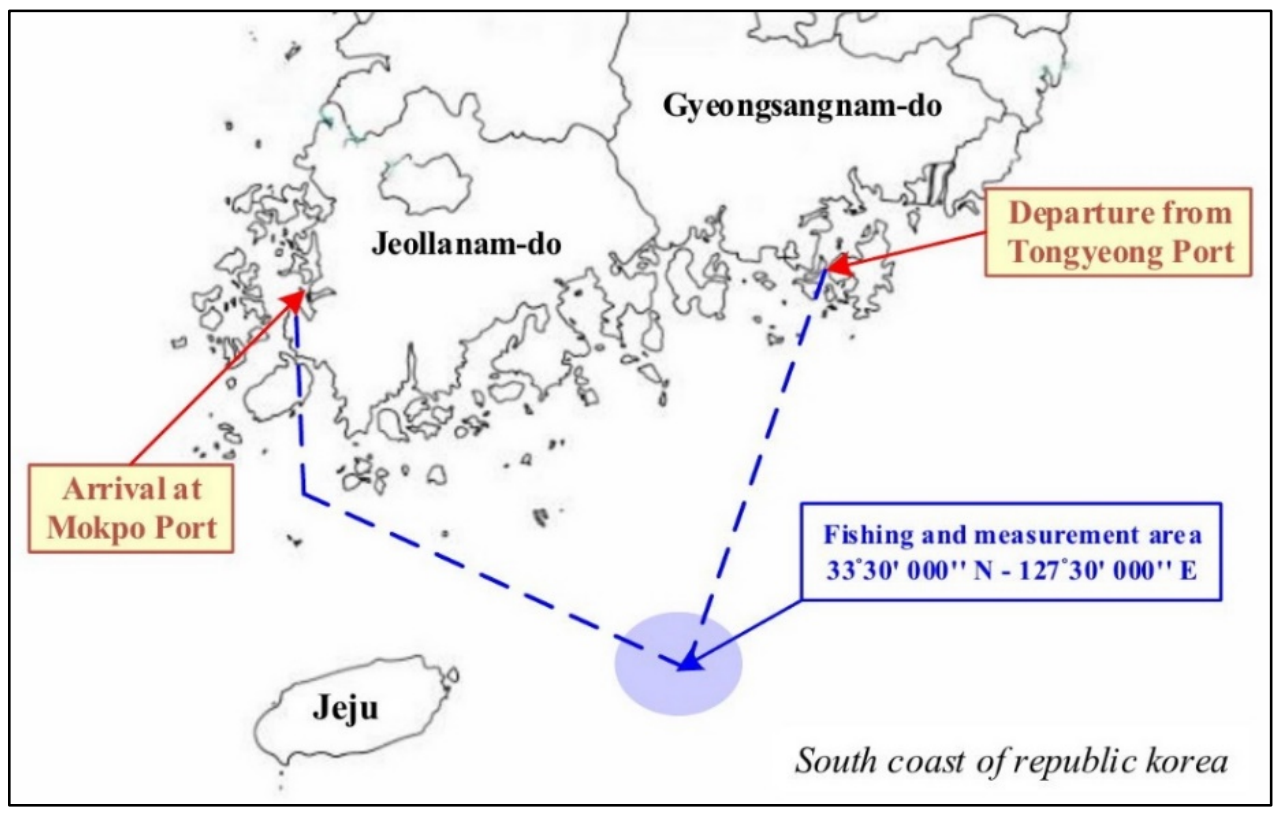

Figure 3. Noise measurement zone and sailing route.

The schematic experimental diagram is briefly illustrated in Figure 4 . Noise measurements were taken in compliance with measurement standards when fishing work and sailing of the vessel were being conducted in a stable state. The data were transferred to a $\mathrm{PC}$, and statistical analysis using actual measurement results and open-source software were subsequently conducted [31].
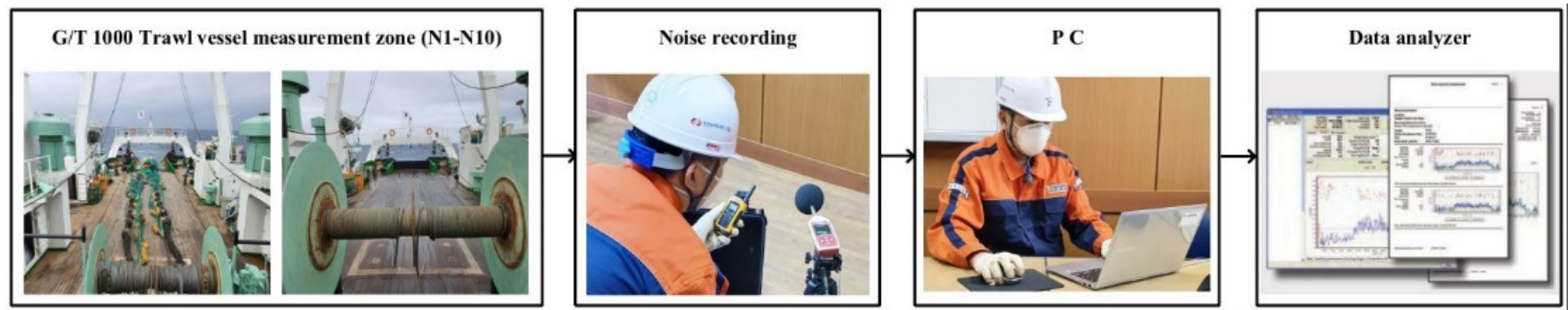

Figure 4. Schematic diagram of the noise measurement experiment.

\section{Results and Discussion}

\subsection{Noise Characteristics for Each Area According to Sailing Conditions}

Figure $5 \mathrm{a}-\mathrm{j}$ shows the classification of noise characteristics for each sailing condition of the fishing vessel by area and then their conversion into 1:3 octave bands.

The results show that the vessel did not exceed the IMO vessel noise acceptance limit in frequency bands of most areas, but the open deck recreation area of the stern (N6) partially exceeded the permitted limit of $75 \mathrm{~dB}(\mathrm{~A})$, and a band of over $200 \mathrm{~Hz}$ was formed in an area. This suggests that the noise level generated in the stern where actual fishing operations take place is higher than the permitted levels for typical vessels, and therefore, safety regulations such as the mandatory wearing of safety equipment or legal regulations regarding noise in fishing vessels must be made to protect the hearing of sailors as soon as possible.

Furthermore, the accommodation areas excluding the open deck recreation area exhibited adequate soundproof effects. Even the engine room areas and the engine control room, the areas most affected by noise, resulted in bands forming in the permitted range between $110 \mathrm{~dB}(\mathrm{~A})$ and $75 \mathrm{~dB}(\mathrm{~A})$, satisfying the regulations regardless of sailing conditions. 


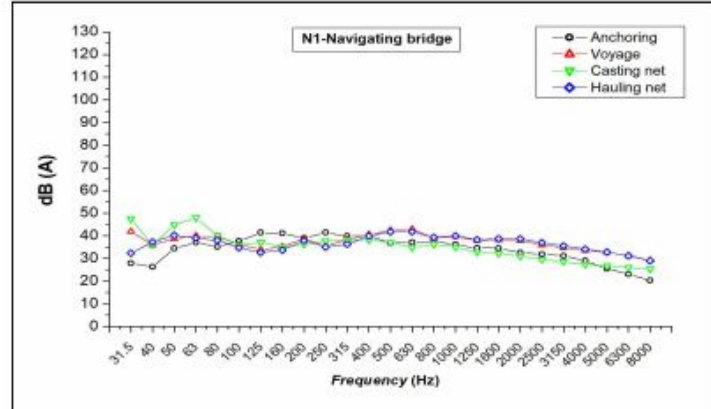

(a)

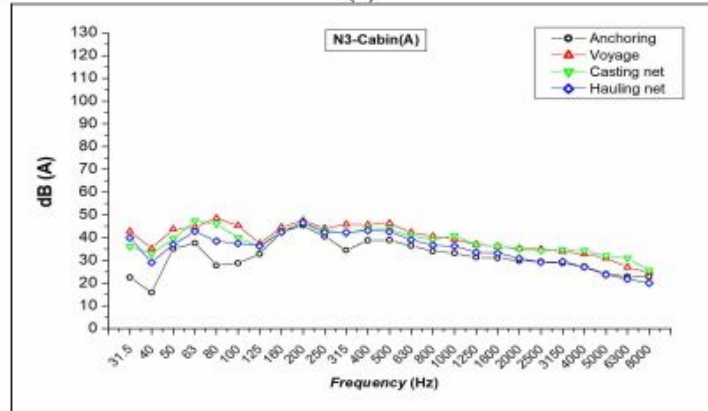

(c)

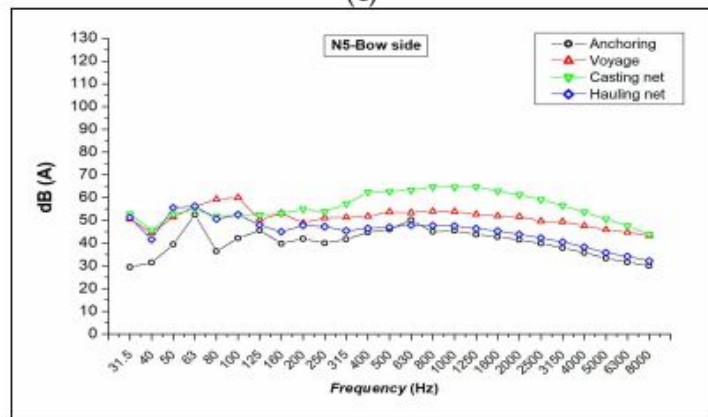

(e)

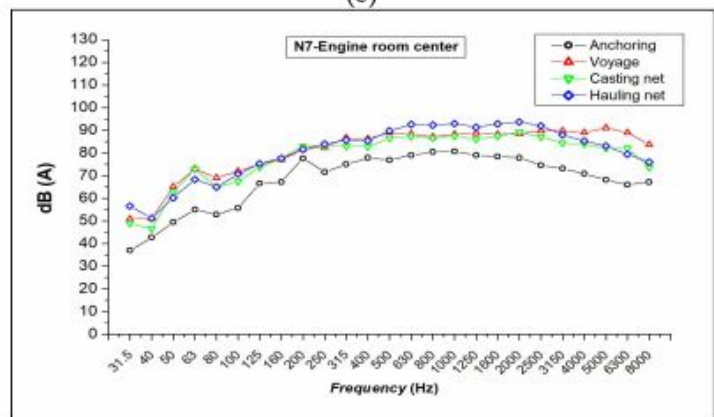

(g)

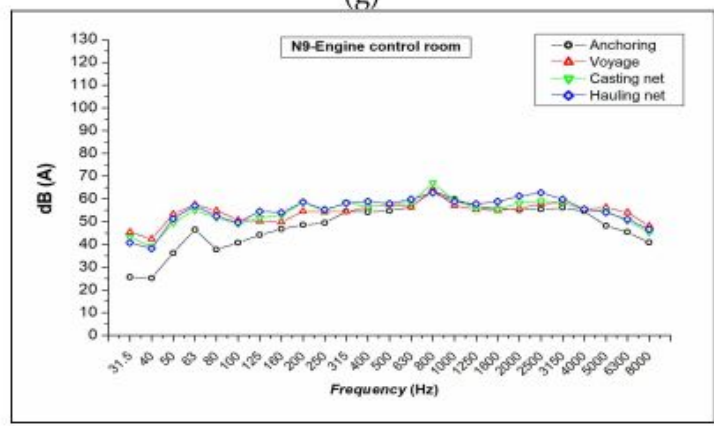

(i)

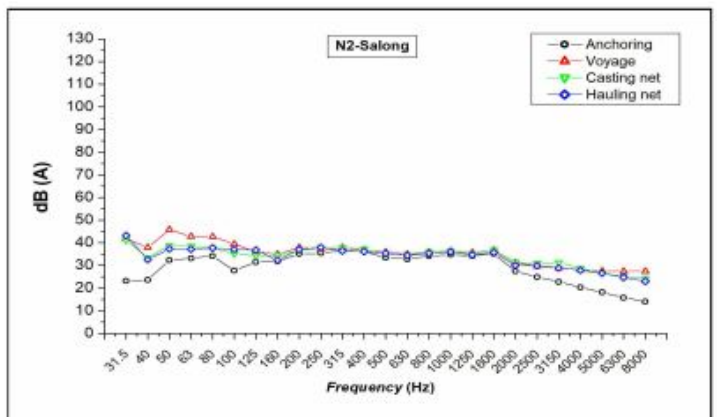

(b)

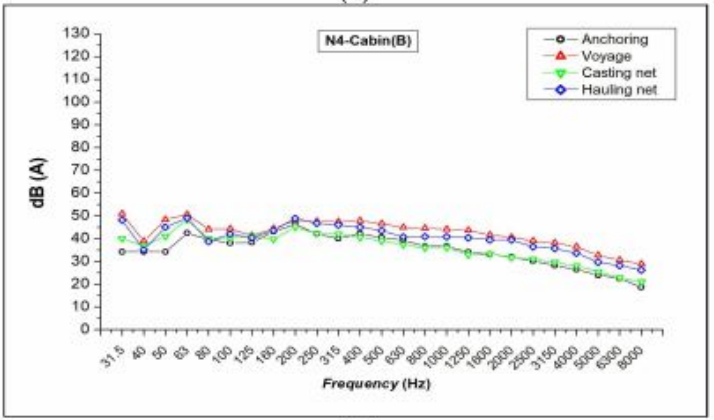

(d)

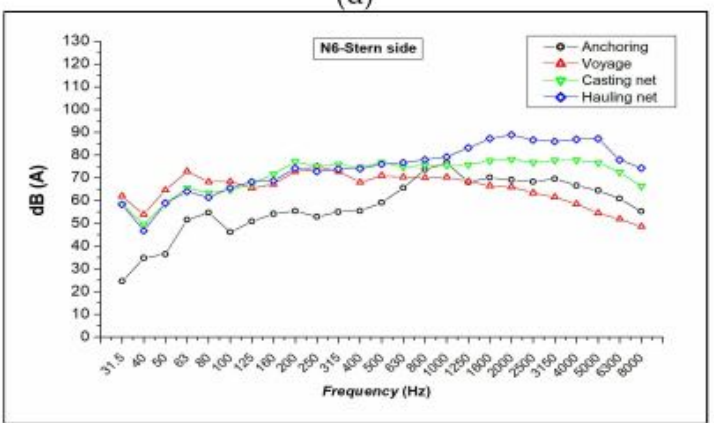

(f)

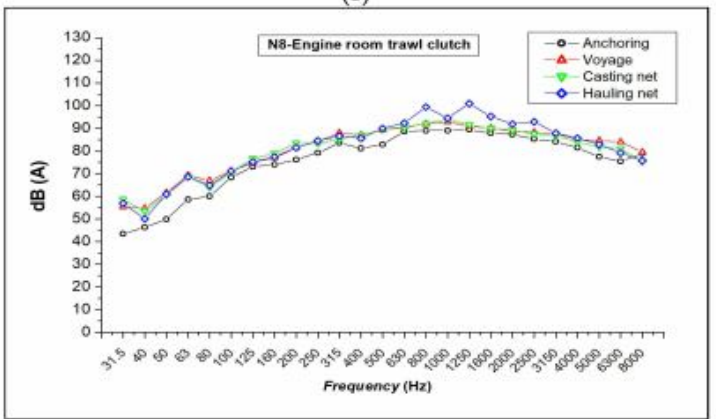

(h)

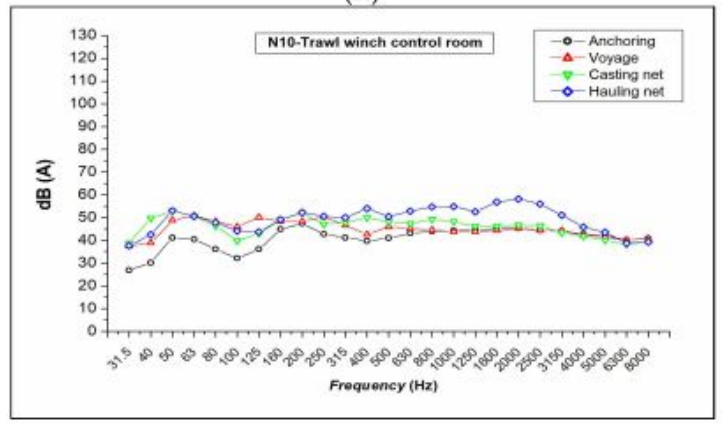

(j)

Figure 5. The 1:3 octave band results for each area. (a) navigating bridge; (b) salong; (c) cabin A; (d) cabin B; (e) bow side; (f) stern side; (g) engine room center; (h) engine room trawl clutch; (i)engine control room; $(\mathbf{j})$ trawl winch control room. 
Overall, the values showed a higher tendency when the vessel was sailing at full speed and during fishing operations compared to anchoring where only essential operational equipment is in use. This phenomenon can be explained by the large load on the main engine during sailing and the winch drum noise, the chain and the lifter, various other devices, and the operation itself impacting the noise levels. Figure 6 summarizes the equivalent synthetic noise.

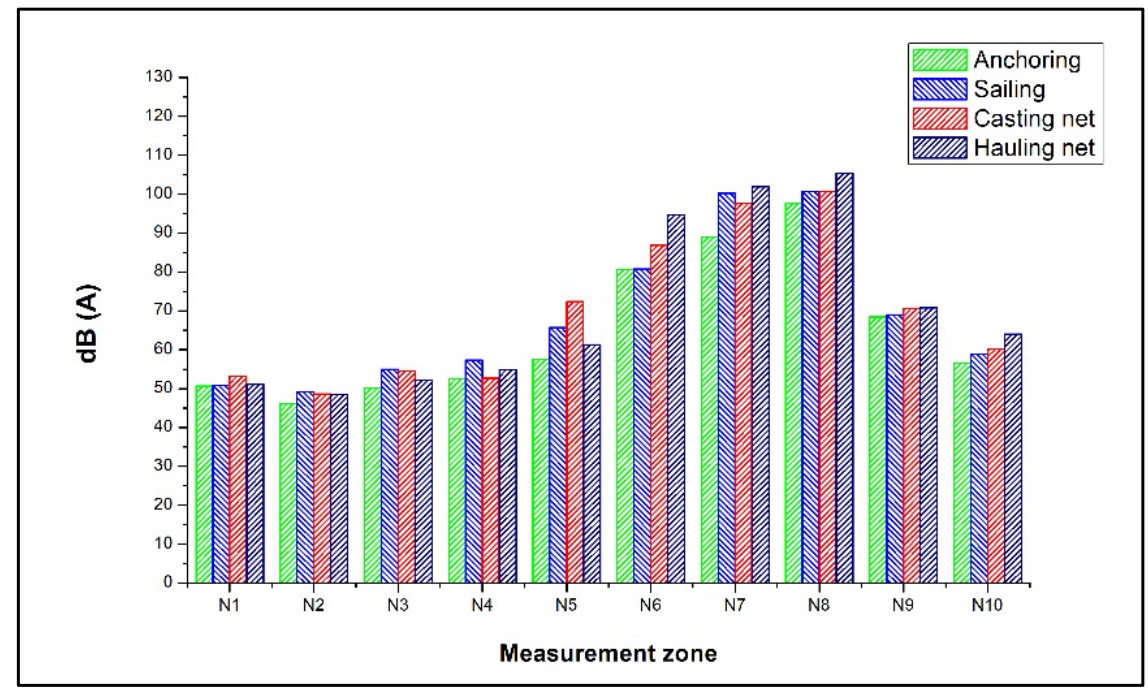

Figure 6. Comparison of synthetic noise for each sailing condition.

\subsection{One-Way Analysis of Variance (ANOVA)}

A computational statistical analysis was conducted based on the practical data acquired. A one-way analysis of variance (ANOVA) was performed to determine whether statistically significant differences exist in noise between areas according to the sailing conditions of the fishing trawler. Since the comparative data satisfy the normality and the number of samples for each group is identical, the Tukey method was used for postvalidation [32]. An open-source software specializing in statistical analysis was selected as the analytical program [33].

Table 5 shows the results of the one-way ANOVA of N1-N10. The analytical results showed a statistically significant difference at the level $(p<0.05)$ between the open deck recreation areas, N5 of the bow side, and N6 of the stern side. Figure 7 represents the standard deviation and synthetic noise of the two areas that exhibited this significant difference. These two areas are marked on their corresponding graphs with red stars.

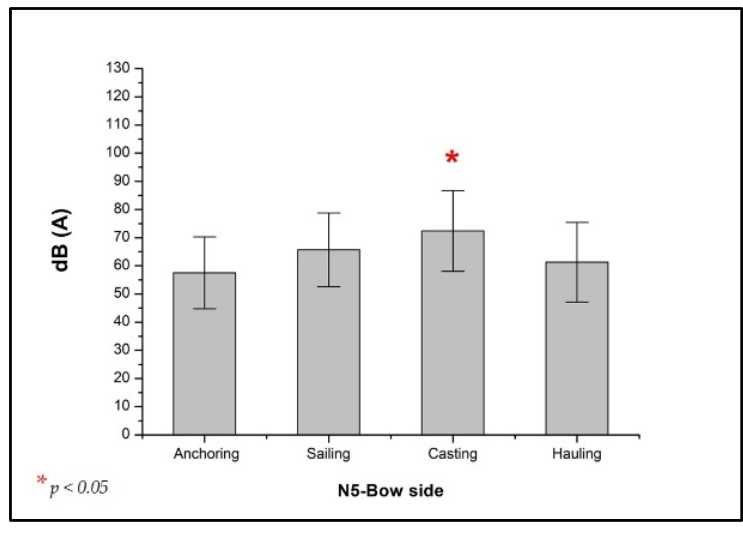

(a)

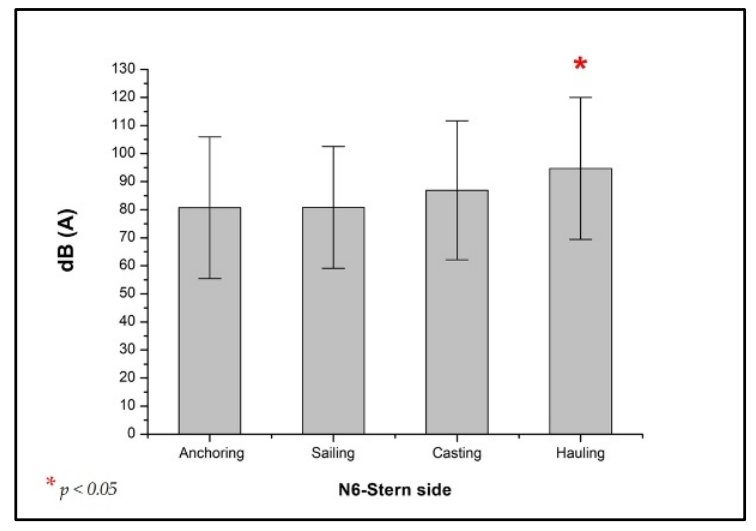

(b)

Figure 7. Significance and post-validation results for each area. (a) Bow side; (b) stern side. 
Table 5. Computerized statistical and analytical results of noise for each area.

\begin{tabular}{|c|c|c|c|c|c|c|c|c|}
\hline \multirow{2}{*}{ Zone } & \multicolumn{4}{|c|}{ Mean (dB (A)) } & \multirow{2}{*}{ SD } & \multirow{2}{*}{$\mathbf{F}$} & \multirow{2}{*}{$p$-Value } & \multirow{2}{*}{$\begin{array}{c}\text { Post- } \\
\text { Hoc(Tukey) }\end{array}$} \\
\hline & Anchoring & Sailing & Casting & Hauling & & & & \\
\hline N1 & 50.7 & 50.8 & 53.2 & 51.1 & 16.557 & 0.634 & 0.595 & - \\
\hline N2 & 46.1 & 49.2 & 48.6 & 48.4 & 15.096 & 2.082 & 0.109 & - \\
\hline N3 & 50.2 & 55.0 & 54.5 & 52.2 & 17.697 & 1.636 & 0.188 & - \\
\hline N4 & 52.5 & 57.3 & 52.7 & 54.9 & 17.693 & 1.257 & 0.295 & - \\
\hline N5 & 57.5 & 65.7 & 72.4 & 61.3 & 13.247 & 3.653 & $0.016 *$ & $A<C$ \\
\hline N6 & 80.7 & 80.8 & 86.9 & 94.7 & 25.277 & 3.177 & $0.029 *$ & $A<H$ \\
\hline N7 & 89.0 & 100.2 & 97.6 & 101.9 & 27.739 & 1.333 & 0.270 & - \\
\hline N8 & 97.6 & 100.7 & 100.6 & 105.3 & 25.917 & 0.277 & 0.842 & - \\
\hline N9 & 68.4 & 69.0 & 70.5 & 70.8 & 21.736 & 0.627 & 0.600 & - \\
\hline N10 & 56.5 & 58.9 & 60.1 & 64.0 & 18.586 & 0.899 & 0.446 & - \\
\hline
\end{tabular}

In the case of N5, the post-validation results showed differences in anchoring and casting, and repeated on-site verification showed that in this fishing vessel, a seawater sanitary pump was operated in the engine room to provide seawater, which enabled smooth winding of the dry net during the casting operation.

At this point, the seawater piping is also connected to the anchor washing on the bow side of the vessel, meaning that the difference arises from the fluid friction noise of seawater only emitted during the casting procedure. However, the noise can be easily remedied by blocking the valve that supplies anchor washing, and the N5 area was then found to have comfortably satisfied the tolerable standards of IMO noise of $75 \mathrm{~dB}(\mathrm{~A})$ in all sailing conditions.

In the case of N6, the actual operation zone in the stern area, the experimental noise value exceeded the permitted limits used in this study, and statistical analysis also showed distinct differences between noise, followed by the post-validation showing significant differences between the anchoring and casting conditions. This resulted in a greater trawl winch load during hauling compared to during casting where the net is lowered below sea level consequently creating greater frictional noise of the hydraulic oil, which was generated at this point.

The chains and plastic buoys that supported the net were deemed to be simultaneously affected by the spontaneous metallic crash and frictional noise, crew voices, and loudspeaker noise within the hull. The actual measurement values were also shown to exceed the IMO permitted levels in the stern area where trawl fishing occurs. Therefore, it was inferred that noise regulations for particular areas within the stern fishing trawlers are required as soon as possible.

The other eight areas all contained deviations but showed no statistically significant differences. This shows that the difference in noise caused by fishing operations or sailing is insignificant in the accommodation areas and control room, which are enclosed areas within the fishing vessel, and all measured values sufficiently satisfied the permitted standard, implying that the indoor accommodation areas of the fishing trawler have adequate soundproof properties.

\section{Conclusions}

After measuring, comparing, and analyzing the noise generated in different sailing conditions of the G/T 1000-ton stern fishing trawler, the following conclusions can be reached.

Since the noise of commercial trawler fishing vessels is very difficult to measure, it appears necessary to make regular noise measurement mandatory after dock repair. 
Among the 10 measured areas of the fishing vessel, the stern, where actual fishing operations take place, was found to generate noise in the $80 \mathrm{~dB}(\mathrm{~A})$ band, thus exceeding the permitted limit of $75 \mathrm{~dB}(\mathrm{~A})$. The other nine areas sufficiently satisfied the IMO acceptance criteria regardless of the sailing conditions. Therefore, it was determined that clear IMO noise regulations for fishing vessels are necessary.

The computational statistical results showed a significant difference $(p<0.05)$ between the open deck recreational areas of the bow and the stern, suggesting that it contributed to the increase in the effect of noise generated during the fishing operation in the fishing vessel. For the bow, the cause of noise was the hydrodynamic noise emitted due to the pump discharge pipe, operated during casting, being connected to the bow, and this can be remedied by blocking the valve. For the stern, there was a difference in noise generated during the hauling operation, where the load of the trawl winch is heavily increased. This was confirmed as frictional noise of the hydraulic oil and metallic frictional noise between the chains and the hull. Therefore, it was deemed necessary for sailors to wear protective equipment in the stern, and related noise regulations must be applied.

The enclosed accommodation areas excluding the bow and the stern did not exhibit any differences regarding noise generated for the fishing operation and sailing conditions of the vessel and satisfied the permitted standards, meaning that the soundproof properties were sufficiently confirmed.

This study was conducted with the aim to improve the sailing environment in terms of the noise generated in the fishing vessel, which could experimentally determine the noise characteristics of the fishing trawler for different sailing conditions. In the future, a variety of further comparative studies on G/T 3000-ton fishing trawlers and extra-large G/T 5000-ton fishing trawlers will be conducted.

Author Contributions: Conceptualization, T.-h.L.; Formal analysis, T.-h.L.; Funding acquisition, B.-k.J.; Investigation, N.-u.L.; Methodology, B.-k.J.; Project administration, B.-k.J.; Resources, T.-h.L.; Supervision, B.-k.J.; Validation, D.-j.L.; Visualization, T.-h.L.; Writing—original draft, T.-h.L.; Writingreview \& editing, T.-h.L. All authors have read and agreed to the published version of the manuscript.

Funding: This research received no external funding.

Institutional Review Board Statement: Not applicable.

Informed Consent Statement: Not applicable.

Data Availability Statement: Not applicable.

Conflicts of Interest: The authors declare no conflict of interest.

\section{References}

1. Jin, H.H.; Kim, J.K. A Study on the Improvement Plan for the Protection of Human Rights of Merchant Ship Seafarers. Marit. Law Rev. 2019, 31, 207-238. [CrossRef]

2. Lee, Y.W.; Kim, W.S. Noise characteristics in a jigging fishing vessel of 300 tons class. J. Korean Soc. Fish. Ocean. Technol. 2012, 48, 91-98. [CrossRef]

3. Hwang, B.K.; Chang, H.Y.; Kim, M.S. Operating status of Korean coastal composite fishing boats by the questionnaire survey. J. Korean Soc. Fish. Ocean. Technol. 2018, 54, 324-332. [CrossRef]

4. International Maritime Organization (IMO). Code on Noise Levels on Board Ships; IMO Resolution A.468 (XII); IMO: London, UK, 1981.

5. Wittekind, D.; Schuster, M. Propeller cavitation noise and background noise in the sea. Ocean Eng. 2016, 120, 116-121. [CrossRef]

6. International Maritime Organization (IMO). Guidelines for the Reduction of Underwater noise from Commercial Shipping to Address Adverse Impacts on Marine Life; IMO MEPC.1/Circ.833; IMO: London, UK, 2014.

7. Park, H.K.; Kim, H.K.; Kim, H.S. Sensitivity Analysis of Environmental Noise by Measuring Noise Characteristics of Air Purifier. Asia-Pac. J. Multimed. Serv. Converg. Art Humanit. Sociol. 2019, 9, 801-812. [CrossRef]

8. Kim, J.S. Noise and Vibration Engineering; Sejinbook Co. Ltd.: Seoul, Korea, 2014.

9. Vuki 'c, L.; Mihanovi 'c, V.; Fredianelli, L.; Plazibat, V. Seafarers' Perception and Attitudes towards Noise Emission on Board Ships. Int. J. Environ. Res. Public Health 2021, 18, 6671. [CrossRef] [PubMed]

10. Bolognese, M.; Fidecaro, F.; Palazzuoli, D.; Licitra, G. Port Noise and Complaints in the North Tyrrhenian Sea and Framework for Remediation. Environments 2020, 7, 17. [CrossRef] 
11. Schenone, C.; Borelli, D.; Pallavidino, E.; Yousseu, A.; Gaggero, T.; Waffo, E. The Port Noise Analysis and Control in Interreg Italy-France Maritime Programme. In INTER-NOISE and NOISE-CON Congress and Conference Proceedings; Institute of Noise Control Engineering: Reston, VA, USA, 2019; Volume 259, pp. 5781-5792.

12. Borelli, D.; Gaggero, T.; Rizzuto, E.; Schenone, C. Holistic control of ship noise emissions. Noise Mapp. 2016, 3, 107-119. [CrossRef]

13. Paschalidou, A.K.; Kassomenos, P.; Chonianaki, F. Strategic Noise Maps and Action Plans for the reduction of population exposure in a Mediterranean port city. Sci. Total Environ. 2019, 654, 144-153. [CrossRef]

14. Alsina-Pagès, R.M.; Socoró, J.C.; Barqué, S. Survey of Environmental Noise in the Port of Barcelona. In Proceedings of the Euronoise-European Conference on Noise Control, Crete, Greece, 27-31 May 2018; Volume 478, pp. 2895-2902. Available online: http:/ /hdl.handle.net/2072/376316 (accessed on 14 August 2021).

15. Murphy, E.; King, E.A. Residential exposure to port noise: A case study of Dublin, Ireland. In Proceedings of the 41st International Congress on Noise Control Engineering, New York, NY, USA, 19-22 August 2012; Available online: http:/ / hdl.handle.net/1019 7/5732 (accessed on 14 August 2021).

16. Nastasi, M.; Fredianelli, L.; Bernardini, M.; Teti, L.; Fidecaro, F.; Licitra, G. Parameters Affecting Noise Emitted by Ships Moving in Port Areas. Sustainability 2020, 12, 8742. [CrossRef]

17. Fredianelli, L.; Nastasi, M.; Bernardini, M.; Fidecaro, F.; Licitra, G. Pass-by characterization of noise emitted by different categories of seagoing ships in ports. Sustainability 2020, 12, 1740. [CrossRef]

18. Park, S.J.; Kim, J.D.; Park, Y.H.; Kim, B.J.; Choi, H.K. Development of Hybrid Silencer to Reduce HVAC Noise. Korean Soc. Mech. Eng. C 2018, 6, 65-73. [CrossRef]

19. Kim, S.H.; Jeon, C.H.; Yeo, J.S. Necessity of Code Adoption Regarding Air-born Noise Emitted by Naval Small Craft and Case Study of Pass-by Measurement Test. J. Korea Soc. Nav. Sci. Technol. 2021, 4, 22-26. [CrossRef]

20. Jung, B.K.; Lee, J.H. A Study on Specific Noise Characteristics of a T/S NARA. J. Fish. Mar. Sci. Educ. 2018, 30, 1696-1702. [CrossRef]

21. Witte, J. Noise from moored ships. In INTER-NOISE and NOISE-CON Congress and Conference Proceedings; Institute of Noise Control Engineering: Reston, VA, USA, 2010; pp. 3202-3211.

22. Kim, M.S.; Shin, H.O.; Kim, M.S.; Hwang, B.K. Boarding Environment of Training Ship KAYA to the Noise during the Voyage. J. Fish. Mar. Sci. Educ. 2010, 22, 218-230.

23. Park, S.W. A Basic Study on the Labor-Saving System for Anchovy Scoop Nets in the Coastal area of Jeju Island in Korea; Jeju National University: Jeju, Korea, 2001.

24. Park, C.S. Characteristics of T/S SAEBADA; Gyeongsang National University: Tongyeong, Korea, 2001.

25. An, Y.S.; Kang, I.K.; Kim, H.S.; Kim, J.C.; Kim, M.S.; Jo, H.J.; Lee, C.K. A study on the manoeuvrability of T/S SAEBADA by real sea trials. J. Korean Soc. Fish. Ocean. Technol. 2005, 41, 289-295.

26. Seo, J.W. Illustrations of Korean Fishing Vessels; National Fisheries Research and Development Institute: Busan, Korea, 2018.

27. Kim, S.H.; Lee, C.K.; Kim, M.S. A study on the characteristics of hull shape parameter of fishing vessel types. J. Korean Soc. Fish. Ocean. Technol. 2020, 56, 163-171. [CrossRef]

28. International Maritime Organization (IMO). Adoption of the Code on Noise Levels on Board Ship; IMO Resolution MSC. 337(91); IMO: London, UK, 2012.

29. Korea Register (KR). Guidance for Noise and Vibration; No. GC-21-E; Korean Register of Shipping: Busan, Korea, 2020.

30. Cirrus Research Plc. User Manual for the Optimus Sound Level Meters; Cirrus Co. Ltd.: North Yorkshire, UK, 2017.

31. Seol, H.S. Statistical Analysis with Jamovi, 2nd ed.; Hakjisa Co. Ltd.: Seoul, Korea, 2021.

32. No, K.S. The Proper Methods of Statistical Analysis for Dissertation; Hanbit Academy Co. Ltd.: Seoul, Korea, 2019.

33. The Jamovi Project. Jamovi Software Version 1.6. 2021. Available online: https:/ /www.jamobi.org (accessed on 30 May 2021). 